E. M. Fonseca Aizpuru, F. J. Nuño Mateo, J. Fernández Palacio, M. J. Menéndez Calderón

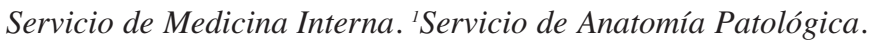
Hospital de Cabueñes. Gijón

1. Pickhardt PJ, Fisher AJ, Balfe DM, Dehner LP and Huettner PC. Desmoplastic small round cell tumor of the abdomen: Radiologic-histopathologic correlation. Radiology 1999; 210: 633-8.

2. Gerald WL, Miller HK, Battifora H, Miettinen M, Silva EG, Rosai J. Intra.-abdominal desmoplastic small round-cell tumor: Report of 19 cases of a distinctive type of high-grade polyphenotypic malignancy affecting young individuals. Am J Surg Pathol 1991; 15: 499-513.

3. Cummings OW, Ulbright TM, Young RH, Del Tos AP, Fletcher CD, Hull MT. Desmoplastic small round cell tumors of the paratesticular region: a report of six cases. Am J Surg Pathol 1997; 21: 219-25.

4. Parkash V, Gerald WL, Parma A, Miettinen M, Rosai J. Desmoplastic small round cell tumor of the pleura. Am J Surg Pathol 1995; 19: 659-65.

5. Intra-abdominal desmoplastic small round cell tumors: CT findings and clinicopathological correlations in 13 cases. Chouli M, Viala J, Dromain C, Fizazi K, Duvillard P, Vanel D. Eur J Radiol 2005; 54: 438-42.

6. Fine RL, Shah SS, Moulton TA, Yu IR, Fogelman DR, Richardson M, et al. Androgen and c-kit receptors in desmoplastic small round cell tumors resistant to chemotherapy: Novel targets for therapy. Cancer Chemother Pharmacol 2007; 59: 429-37.

7. Bond M, Bernstein ML, Pappo A, Schultz KR, Krailo M, Blaney SM, Adamson PC. A phase II study of imatinib mesylate in children with refractory or relapsed solid tumors: A children's Oncology Group study. Pediatric Blood Cancer 2007; 29 (epub ahead of print).

8. Mazuryk M, Paterson AHG, Temple W, Arthur K, Crabtree T, Stewart DA. Benefit of aggressive multimodality therapy with autogous stem cell ssuport for intra-abdominal desmoplastic small round cell tumor. Bone Marrow Transplant 1998; 21: 961-3.

\section{Parálisis bilateral del sexto y unilateral del tercer par craneal después de una punción lumbar}

\section{Sr. Director:}

La punción lumbar es un método diagnóstico común en medicina. Las parálisis de los nervios craneales son una complicación raramente descrita después de una punción lumbar (1-3). El más frecuentemente afectado es el sexto par craneal entre los 4 y 14 días post-punción y generalmente se resuelve espontáneamente en semanas o meses (2). La parálisis del tercer par craneal es muy rara. Se describe una paciente con parálisis del sexto y paresia del tercer par craneal en el ojo derecho y parálisis del sexto par en el ojo izquierdo después de una punción lumbar.

Paciente de 62 años con antecedentes de hipertensión craneal idiopática. Se le realiza punción lumbar con aguja de $22 \mathrm{G}$ entre L2-L3 sin complicaciones. En el primer día post-punción la paciente tuvo una cefalea intensa y difusa que empeoraba cuando intentaba levantarse. Al quinto día, refería diplopia en la visión lateral. El estudio neuro-oftalmológico mostró una paresia del tercer par craneal derecho afectando selectivamente al músculo recto medio y una parálisis bilateral del sexto par craneal. No había ptosis, y la función del elevador de ambos párpados era de $12 \mathrm{~mm}$. Su estado neurológico y los signos vitales eran normales. La TAC craneal no detectó patología. La paciente fue tratada de forma conservadora con reposo en cama. El dolor de cabeza cedió gradualmente y las parálisis fueron mejorando hasta que se resolvieron en 10 semanas.

El efecto secundario más común después de una punción lumbar es la cefalea por hipotensión del líquido cefalorraquídeo (síndrome de hipotensión intracraneal) generalmente por escape a través de pequeños desgarros en el sitio de punción (4). Las parálisis de los nervios craneales post-punción no son comunes y aunque todos los nervios craneales pueden ser afectados, excepto I, IX y X, el sexto par es el más afectado porque es uno de los nervios más largos en su recorrido periférico (4). El tercer par craneal sale del mesencéfalo con una organización topográfica de los fascículos y las fibras destinadas a inervar el músculo recto medial localizadas en un plano medio-caudal (5). La paciente descrita es interesante porque la combinación de parálisis del sexto y tercer pares craneales en un ojo y parálisis del sexto par en el ojo adelfo después de una punción lumbar es una complicación tan rara que no hemos podido encontrar en la bibliografía casos similares. Especial importancia tiene la posición del paciente después de una punción lumbar, poniéndose en dúbito supino para prevenir escapes de líquido cefalorraquídeo en la zona de punción (4). En esa situación, el desplazamiento inferior del cerebro puede explicar las parálisis de los nervios craneales. Por lesión vascular o por desmielinización la tracción durante la fase aguda pudo ser la responsable de la parálisis de los nervios craneales en nuestro paciente.

\section{M. Asensio-Sánchez}

Servicio de Oftalmología. Hospital General. Servicio Castellano Leonés de Salud. Medina del Campo. Valladolid

1. Thomke F, Mika-Gruttner A, et al. The risk of abducens palsy after diagnostic lumbar puncture. Neurology 2000; 54: 768-9.

2. Follens I, Godts D, Evens PA, et al. Combined fourth and sixth cranial nerve palsy after lumbar puncture: A rare complication. A case report. Bull Soc Belge Ophtalmol 2001; 281: 29-33.

3. Niedermuller U, Trinka E, Bauer G. Abducens palsy after lumbar puncture. Clin Neurol Neurosurg 2002; 104: 61-3.

4. Kose KC, Cebesoy O, Karadeniz E, et al. Eye problem following foot surgery - abducens palsy as a complication of spinal anesthesia. 2005; 7: 15 .

5. Ksiazek SM, Slamovits TL, Rosen CE, et al. Fascicular arrangement in partial oculomotor paresis. Am J Ophthalmol 1994; 118: 97-103.

\section{Comentario sobre un caso de síndrome de Heyde}

\section{Sr. Director:}

En 1958 se describe, por primera vez, la asociación entre estenosis valvular aórtica (EA) calcificada y hemorragia digestiva recurrente, que fue llamada Síndrome de Heyde $(\mathrm{SH})$, posteriormente se identifican angiodisplasias intestinales (AI) como origen del sangrado (1). Presentamos un caso con esta asociación.

Mujer de 51 años, diabética, hipertensa, con soplo sistólico conocido pero no estudiado. En el último año episodios repetidos y severos de rectorragias. Enema opaco, estudio gastroduodenal, gastroscopia y gammagrafía con hematíes marcados sin hallazgos; la paciente rechazó colonoscopia y arteriografía. En ecocardiograma $2 \mathrm{D}$ aparece válvula aórtica fibrocalcificada y deses- 